\title{
LEUKOCYTE LIPID PEROXIDATION, SUPEROXIDE DISMUTASE AND CATALASE ACTIVITIES OF TYPE 2 DIABETIC PATIENTS WITH RETINOPATHY
}

\author{
Naciye Kurtul', Ebubekir Bakan ${ }^{2}$, Hülya Aksoy ${ }^{2}$, Orhan Baykal ${ }^{3}$
}

KSU, Kahramanmaras, Faculty of Science, Turkey: Department of Chemistry'; Medical School, Atatürk University, Erzurum, Turkey: Department of Biochemistry ${ }^{2}$, Department of Ophtalmology ${ }^{3}$

\begin{abstract}
Summary: Increased oxidative stress might play an important role in the initiation and progression of diabetic complications. The present study has been undertaken to investigate whether there is any relationship between retinopathy degree and leukocyte superoxide dismutase (SOD) and catalase (CAT) activities and lipid peroxidation (LPO) in diabetic individuals with type 2 diabetic retinopathy. Patients were groupped with respect to the degree of retinopathy. Leukocyte malondialdehyde (MDA) levels, and SOD and CAT activities were measured in patients with type 2 diabetes mellitus $(\mathrm{n}=41)$ and nondiabetic healthy controls $(\mathrm{n}=23)$. Leukocyte $\mathrm{LPO}$ of the type 2 diabetic patients with retinopathy was significantly increased $(p<0.001)$, whereas SOD and CAT activities were decreased $(\mathrm{p}<0.001$ and $\mathrm{p}<0.001$, respectively) compared to those of controls. MDA concentrations rose while SOD and CAT activities fell with increasing severity of diabetic retinopathy, altough there was no significant difference in comprasion of the parameters mentioned above between the diabetic patients with and without retinopathy. Our results show that leukocytes in patients with type 2 diabetic retinopathy are affected by oxidative stress which might be contribute to pathogenesis of diabetic retinopathy. Prospective studies are needed to evaulate the relationship between the leukocyte antioxidants status and DR.
\end{abstract}

Key words: Diabetes; Diabetic retinopathy; Lipid peroxidation; Superoxide dismutase; Catalase

\section{Introduction}

Increasing evidence suggests that increased oxidative stress, associated with diabetes mellitus, might play an important role in the initiation and progression of diabetic complications such as retinopathy, neuropathy and nephropathy $(2,5,28)$. This hypothesis is supported by evidence that many biochemical pathways e.g., glucose autoxidation, polyol pathway, prostanoid synthesis and protein glycation, tightly associated with hyperglycemia, can increase the production of free radicals (5).

Diabetic retinopathy (DR) is the most common cause of legal blindness in individuals between the ages of 20 and 65 years. DR is a microangiopathy affecting the retinal precapillary arterioles, capillaries and venules. However, larger vessels may also be involved. Retinopathy has features of both microvascular occlusion and leakage. Clinically, the three main types of DR are background, preproliferative and proliferative (12). Altough hyperglycaemia has been identified as the major underlying factor of retinopathy, the complex cascade of events leading to vascular occlusions remains undefined. Potential pathogenetic mechanisms include platelet dysfunction, increased blood viscosity in as- sociation with impaired cell deformability and pathologic leukocyte/endothelium interaction (8). Chronic hyperglycemia affects cellular and matrix function by a variety of mechanisms such as increased polyol pathway activity, altered intracellular redox state, activation of protein kinase $\mathrm{C}$, non-enzymatic glycation and increased free radical damage $(8,9,15)$.

Reactive oxygen species, such as superoxide radical, hydrogen peroxide, and hydroxyl radical, are constantly formed by activated phagocytes and by other mechanisms in the human body and removed by antioxidant defenses. Popular antioxidants include vitamins $\mathrm{E}$ and $\mathrm{C}$, carotenoids, glutathione, ubichinol, uric acid, and antioxidant enzymes. Among these enzymes, superoxide dismutase (SOD) catalyses dismutation of superoxide anion $\left(\mathrm{O}_{2}^{-\cdot}\right)$ into $\mathrm{H}_{2} \mathrm{O}_{2}$ and both catalase (CAT) and glutathione peroxidase (GSH-Px) detoxify $\mathrm{H}_{2} \mathrm{O}_{2}$ and convert lipid hydroperoxides to nontoxic alcohols $(6,7,11)$.

There are several reports on plasma $(16,21)$ and erythrocyte $(14,31)$ lipid peroxidation (LPO) and antioxidant enzymes in diabetes, but few studies have been devoted to leukocyte antioxidants (1). Also, there is no report available on leukocyte antioxidant enzymes and LPO in DR. 
Therefore, the present study has been undertaken to investigate whether there is any relationship between retinopathy degree and leukocyte SOD and CAT activities and LPO in diabetic individuals with type 2 DR.

\section{Materials and Methods}

Fourty-one type-2 diabetic patients were included in this study (19 males, 22 females aged 43-74 years). Patients were classified into subgroups with respect to the degree of retinopathy after examination by a specialist in the ophthalmology department, including no diabetic retinopathy (NDR), background diabetic retinopathy (BDR), preproliferative diabetic retinopathy (prePDR), and proliferative diabetic retinopathy (PDR). Following definitions were used: BDR consists of microaneurysms, dot and blot hemorrhages, hard exudates and retinal edema; pre-PDR consists of cotton wool spots, venous changes such as dilation, beading, looping, and sausagelike segmentation, arteriolar narrowing and large dark blot hemorrhages; PDR consists of neovascularization, vitreous changes, and integral or preretinal hemorrhages. Informed consent was obtained from all subjects. The control group consisted of 23 healthy controls ( 10 males, 13 females aged $37-63$ years). The absence of diabetes was checked in these individuals before each blood sample taken, and none of the subjects in this study had hypertension and no one was smoking and taking alcohol. Characteristics of subjects are shown in Table 1. Blood samples $(20 \mathrm{~mL})$ were collected by venipuncture in vacutainer tubes containing heparin. For isolation of leukocytes, red blood cells were sedimented with dextran. The white blood cell-rich supernatant was centrifuged at $200 \mathrm{x}$ g for five minutes, thus leukocytes were pelletted. The pellet was washed three times with $3 \mathrm{~mL}$ of saline. The contaminating red cells were removed by osmotic shock (13). For this pro- cedure, $2 \mathrm{~mL}$ of chilled, distilled water was added to the pellet, followed, $20 \mathrm{sec}$ later, by additional $2 \mathrm{~mL}$ of hypertonic saline $(1.8 \% \mathrm{NaCl})$. Following centrifugation, the final pellet was suspended in $1 \mathrm{~mL}$ izotonic saline. LPO analysis was performed on this portion. LPO was assayed by measurement of malondialdehyde (MDA). MDA, an end product of fatty acid peroxidation, reacts with thiobarbituric acid (TBA) to form a colored complex that has maximum absorbance at $532 \mathrm{~nm}$ (4). The concentration of MDA was calculated by the absorbance coefficient of MDA-TBA complex $1.56 \times 105 \mathrm{~cm}^{-1} \mathrm{M}^{-1}$ and expressed as nmoles of MDA per miligram of the protein.

Leukocytes were lysed by repeated thawing and freezing after addition of $0.2 \%$ Triton-X for protein determination and enzymatic analyses. Protein content of the supernatant was determined with Lowry method (18). CAT and SOD activities were measured as previously described Luck by and Sun, respectively $(19,27)$. Activities of the enzymes were calculated as $\mathrm{U} / \mathrm{mg}$ protein for SOD and as $\mathrm{k} / \mathrm{mg}$ protein for CAT. The principle of the assay for the CAT activity is based on the determination of the rate constant $\left(\mathrm{s}^{-1}, \mathrm{k}\right)$ of hydrogen peroxide decomposition by CAT enzyme.

Blood fasting glucose was determined by routine methods using glucose oxidase in an autoanalyser (Hitachi 717: Hitachi, Tokyo, Japan). $\mathrm{HbA}_{1 \mathrm{c}}$ was estimated by a commercially available kit based on column chromatography (Biosystems, Barcelona, Spain). All the experimental procedures were performed at $+4{ }^{\circ} \mathrm{C}$.

Data are expressed as mean \pm standard deviation (SD). Statistical analyses were conducted by analysis of variance (ANOVA) following by Tukey test. Pearson correlation analysis was used to detect relationship between variables in the diabetic and control groups. The criterion for statistical significance was $p<0.05$.

Tab. 1: Characteristics of subjects and comparison of parameters of patients with diabetes and controls.

\begin{tabular}{|c|c|c|c|c|c|c|c|}
\hline & $\begin{array}{l}\text { Control } \\
(n=23)\end{array}$ & $\begin{array}{c}\text { NDR } \\
(n=16)\end{array}$ & $\begin{array}{l}\text { BDR } \\
(n=7)\end{array}$ & $\begin{array}{c}\text { PrePDR } \\
(n=8)\end{array}$ & $\begin{array}{c}\text { PDR } \\
(n=10)\end{array}$ & $\begin{array}{c}\text { DM } \\
(n=41)\end{array}$ & $\begin{array}{l}\text { T2DR } \\
(n=25)\end{array}$ \\
\hline Age (years) & $53.55 \pm 6.72$ & $59.00 \pm 6.96$ & $55.85 \pm 9.61$ & $54.25 \pm 8.03$ & $57.00 \pm 5.37$ & $57.04 \pm 7.29$ & $55.80 \pm 7.35$ \\
\hline $\begin{array}{l}\text { Duration of DM } \\
\text { (years) }\end{array}$ & - & $2.62 \pm 1.85^{\mathrm{a}}$ & $5.85 \pm 4.77^{\mathrm{a}}$ & $11.75 \pm 3.99^{\mathrm{a}, \mathrm{c}}$ & $15.10 \pm 4.43^{\mathrm{a}, \mathrm{c}}$ & $8.00 \pm 6.30^{\mathrm{a}, \mathrm{c}}$ & $11.44 \pm 5.69^{\mathrm{a}, \mathrm{c}}$ \\
\hline $\mathrm{HbA}_{1 \mathrm{c}}(\%)$ & $5.73 \pm 1.51$ & $7.94 \pm 1.94^{\mathrm{e}}$ & $8.14 \pm 2.72^{\mathrm{d}, \mathrm{e}}$ & $9.05 \pm 1.16^{b}$ & $11.58 \pm 2.05^{\mathrm{a}, \mathrm{c}, \mathrm{g}}$ & $9.08 \pm 2.25^{\mathrm{a}}$ & $9.80 \pm 2.16^{\mathrm{a}, \mathrm{f}}$ \\
\hline $\begin{array}{l}\text { SOD } \\
\text { (U/mg protein) }\end{array}$ & $21.91 \pm 8.81$ & $11.50 \pm 3.74^{\mathrm{a}}$ & $10.34 \pm 2.45^{\mathrm{a}}$ & $7.30 \pm 1.83^{\mathrm{a}}$ & $6.48 \pm 2.31^{\mathrm{a}}$ & $9.25 \pm 3.58^{\mathrm{a}}$ & $7.82 \pm 2.68^{\mathrm{a}}$ \\
\hline $\begin{array}{l}\text { CAT } \\
\text { (k/mg protein) }\end{array}$ & $\begin{array}{l}2.04 \cdot 10^{-2} \pm \\
9.38 \cdot 10^{-3}\end{array}$ & $\begin{array}{c}7.94 \cdot 10^{-3} \pm \\
\pm 3.00 \cdot 10^{-3 a}\end{array}$ & $\begin{array}{c}7.29 \cdot 10^{-3} \pm \\
\pm 3 \cdot 15 \cdot 10^{-3} \mathrm{a}\end{array}$ & $\begin{array}{l}5.88 .10^{-3} \pm \\
1.46 .10^{-3} \mathrm{a}\end{array}$ & $\begin{array}{l}5.30 .10^{-3} \pm \\
2.41 .10^{-3} \mathrm{a}\end{array}$ & $\begin{array}{l}6.78 .10^{-3} \pm \\
2.80 .10^{-3} \mathrm{a}\end{array}$ & $\begin{array}{l}6.04 \cdot 10^{-3} \pm \\
2.44 .10^{-3} \mathrm{a}\end{array}$ \\
\hline $\begin{array}{l}\text { MDA } \\
\text { (nmol/mg protein) }\end{array}$ & $2.42 \pm 0.60$ & $3.95 \pm 0.98^{\mathrm{a}, \mathrm{d}}$ & $4.19 \pm 1.11^{\mathrm{b}}$ & $4.30 \pm 0.76^{\mathrm{a}}$ & $5.54 \pm 1.72^{\mathrm{a}}$ & $4.45 \pm 1.31^{\mathrm{a}}$ & $4.76 \pm 1.42^{\mathrm{a}}$ \\
\hline
\end{tabular}

a: $p<0.001$ vs controls, b: $p<0.01$ vs controls, c: $p<0.001$ vs NDR, $\mathrm{d}: p<0.01$ vs PDR, e: $p<0.05$ vs controls, f: $p<0.05$ vs NDR, g: $p<0.05$ vs prePDR.

Values represent means \pm SD; DM, Diabetes Mellitus; NDR, diabetic group no diabetic retinopathy; BDR, background diabetic retinopathy; prePDR, preproliferative diabetic retinopathy; PDR, proliferative diabetic retinopathy; T2DR, type 2 diabetic retinopathy; SOD, superoxide dismutase; CAT, catalase; MDA, malondialdehyde. 


\section{Results}

Results are given in Table 1. Leukocyte LPO of the patients with type $2 \mathrm{DM}$ was significantly increased $(4.45$ $\pm 1.31 \mathrm{vs} 2.42 \pm 0.60 \mathrm{nmol} / \mathrm{mg}$ protein, $\mathrm{p}<0.001$ ], whereas SOD and CAT activities were decreased $(9.25 \pm 3.58$ vs $21.91 \pm 8.81 \mathrm{U} / \mathrm{mg}$ protein, $\mathrm{p}<0.001$ and $6.78 .10^{-3}$ $\pm 2.80 .10^{-3}$ vs. $2.04 .10^{-2} \pm 9.38 .10^{-3} \mathrm{k} / \mathrm{mg}$ protein; $\mathrm{p}<$ 0.001 , respectively) compared with those of controls. In addition, there was an inverse relationship between the severity of DR and SOD and CAT activities. MDA concentrations rose $(4.19 \pm 1.1$ for $\mathrm{BDR} ; 4.3 \pm 0.76$ for pre-PDR; and $5.54 \pm 1.7 \mathrm{nmol} / \mathrm{mg}$ protein for PDR), while SOD (10.3 \pm 2.4 for BDR; $7.3 \pm 1.8$ for pre-PDR; and $6.4 \pm 2.3 \mathrm{U} / \mathrm{mg}$ protein for PDR) and CAT (7.2.10 $0^{-3} \pm 3.1 .10^{-3}$ for BDR; 5.8.10-3 $\pm 1.4 .10^{-3}$ for pre-PDR; and $5.3 .10^{-3} \pm 2.4 .10^{-3}$ $\mathrm{k} / \mathrm{mg}$ protein for PDR) activities fell with increasing severity of DR. However, MDA levels and SOD and CAT activities were not different in type 2 diabetic patients with retinopathy compared without retinopathy.

In correlation analysis, leukocyte MDA levels were correlated with $\mathrm{HbA}_{1 \mathrm{c}}$ and duration of DM ( $\mathrm{r}=0.410 ; \mathrm{p}<0.01$ and $r=0.362 ; p<0.05$, respectively) in diabetics. In addition, duration of DM was correlated with SOD activities and $\mathrm{HbA}_{1 \mathrm{c}}(\mathrm{r}=-0.379 ; \mathrm{p}<0.05$ and $\mathrm{r}=0.55$; $\mathrm{p}<0.01$, respectively) in diabetics. There was, however, no significant correlation between studied parameters in patients with type $2 \mathrm{DR}$ except for duration of $\mathrm{DM}$ and $\mathrm{HbA}_{1 \mathrm{c}}$.

\section{Discussion}

DR is a highly specific vascular complication of diabetes mellitus. Oxidative stress is believed to play a significant role in the development of diabetic retinopathy. Uzel et. al. demonstrated the elevation of lipid peroxide levels in plasma and erythrocyte of diabetic patients with retinopathy on comparison to without retinopathy and to no diabetic control group, and therefore it is suggested that the elevation of LPO in the blood of diabetics may be a cause of retinopathy (31). Also, Kowluru et. al. demonstrated elevated lipid peroxides in retina and plasma from diabetic rats (16). In another study, Akkus and co-workers have shown that leukocyte lipid peroxidation of diabetics was increased (1). Impaired polymorfnuclear leukocyte (PMNL) functions have been observed in poorly controlled diabetics (20). On the other hand, activation of leukocytes and monocytes has been associated with retinal vascular occlusion in diabetic rats (24), which is important source of oxygen free radicals. However, in literature review, we could find no study related to leukocyte antioxidants and LPO in the DR.

In this study, an increase in LPO was associated with severity of DR, with the highest levels being in the PDR group. We also observed that the leukocyte SOD and CAT activities in patients with type 2 DR were lower than those in nondiabetic healthy subjects and than those in diabetic patients without retinopathy. In addition, severity of DR was inversely related to leukocyte SOD and CAT levels, and they were the lowest in the PDR group for both parameters.

Du et. al. showed that diabetes-like glucose concentration increases superoxide production in retinal cells, and the superoxide contributes to impaired viability and increased cell death under those circumstances (3). Yang et. al. reported that high concentrations of glucose cause generation of superoxide; a consequent prolonged superoxide excess can impair cellular function (33). On the other hand, generation of oxygen free radicals during interactions which related with hyperglycemia has been confirmed by the findings of increased superoxide anion radical production in both plasma and PMNL (32). Furthermore, exposure of endothelial cells to high glucose leads to augmented production of superoxide anion, which may quench nitric oxide, a potent endothelium-derived vasodilator that participates in the general homeostasis of the vasculature (5). Altough SOD provides effective intracellular defence against superoxide radical-mediated toxicity, this scavenging system might be impaired in diabetes due to diminished synthesis and/or deactivation of the enzyme by glycation. In previous studies, there are inconsistent findings concerning leukocyte SOD activity in diabetes. Vučić found that SOD activity in lymphocytes and PMNL was significantly lower than that of controls in both type 1 and type 2 DM (32). Also, Uchimura et. al. found that $\mathrm{Cu}, \mathrm{Zn}-\mathrm{SOD}$ and $\mathrm{Mn}$ SOD activities in neutrophils and lymphocytes were significantly lower in patients with type 2 DM than in healthy controls (30). Our results confirm the results of these study. In contrast, Akkus reported no significant change in leukocyte SOD activity in type 2 diabetic patients (1).

On the other hand, $\mathrm{H}_{2} \mathrm{O}_{2}$, an important reactive oxygen species in human pathology, is metabolized to $\mathrm{H}_{2} \mathrm{O}$ by CAT (7). In several studies, plasma, erythrocyte, leukocyte and tissue CAT activities are reported in diabetic humans and rats, but findings of these studies are controversial. For example, Strother reported that decreased hepatic and increased cardiac CAT activity were observed in diabetic rats when compared to normal (26). Kesavulu reported that erythrocyte CAT activity was increased in the type 2 diabetic patients compared with those in controls (14). Türk found that plasma CAT activity was significantly decreased in the type 2 diabetic patients when compared with the control group (29). In spite of this, Muchova reported that CAT activity showed no significant difference in PMNL from patients with type 2 DM when compared with controls (22). The finding does not agree with our results, since in our study, CAT activity was lower in patients with or without DR than that of controls. Additionally, there was an inverse relationship between the severity of DR and CAT activitiy. The significant decrease in CAT activity could be due to glycation of the enzyme or generation of $\mathrm{H}_{2} \mathrm{O}_{2}$ in large amounts.

The decrease reactivity of the SOD and increase in $\mathrm{H}_{2} \mathrm{O}_{2}$ concentrations lead to generation of the hydroxyl radicals from the Fenton's type reaction. The subsequent 
hydroxyl radical induces the generation of superoxide radical, leading to peroxidation (23).

In addition, erythrocyte $\mathrm{HbA}_{1 \mathrm{c}}$, a marker of glycation and an important risk factor for the progression for DR, was correlated with leukocyte MDA in diabetics in present study. This finding is in accordance with that of Jain (10), who found erythrocyte membrane LPO to be increased and correlated with $\mathrm{HbA}_{1 \mathrm{c}}$ levels in diabetics but inconsistent with that of Akkus and co-workers (1), who found no correlation between leukocyte LPO and $\mathrm{HbA}_{1 \mathrm{c}}$. However, a weak correlation was found between $\mathrm{HbA}_{1 \mathrm{c}}$ and SOD and CAT activities in diabetics in our study. In addition, we found the significant correlations between SOD and MDA and duration of diabetes, which is a significant risk factor for the development of retinopathy (15).

Several controlled clinical trials have documented the efficiency of $\alpha$-tocoferol in minimizing the retinopathy, suggesting a role for LPO (6). It was reported that diabetesinduced increased oxidative stress in the retina can be inhibited by dietary supplementation with antioxidants (16, 17). Also, vitamin $C$ has been shown to help improve the effects of retinopathy (25).

From these previous reports, it has been understood that there is a close relationship between the leukocyte function disorders and diabetes and DR and also that oxidative stress plays an important role in the progression of the retinopathy. Our results, however, show the contribution of the inadequate antioxidative defence in leukocytes to the progression of retinopathy in diabetes. As far as we are concerned, it is our study that shows the relation of leukocyte antioxidants and LPO to DR.

It can be concluded from our results that leukocyte CAT and SOD activities decrease and LPO increases in type 2 diabetic patiens with or without retinopathy. Morever, severity of retinopathy is related to the defects of antioxidant protection. Therefore, one should consider that the increase in production of free radicals and impairment of the antioxidative defense mechanisms have a role on the pathogenesis of DR. However, further studies are needed to confirm the relationship of the antioxidant status and progression of DR.

\section{References}

1. Akkus I, Kalak S, Vural H et al. Leukocyte LPO,superoxide dismutase, glutathione peroxidase and serum and leukocyte vitamin $\mathrm{C}$ levels of patients with type II diabetes mellitus. Clin Chim Acta 1996;244:221-7.

2. Armstrong AM, Chestnutt JE, Gormley MJ, Young IS. The effect of dietary treatmenton lipid peroxidation and antioxidant status in newly diagnosed noninsulin dependent diabetes. Free Radic Biol Med 1996;21(5):719-26.

3. Du Y, Miller CM, Kern TS. Hyperglycemia increases mitochondrial superoxide in retina and retinal cells. Free Radic Biol Med 2003;35(11):1491-9.

4. Draper HH and Hadley M. Malondialdehyde determination as index of lipid peroxidation. Methods Enzymol 1990;186:421-31.

5. Giugliano D, Ceriello A, Paolisso G. Oxidative stress and diabetic vascular complications. Diabetes Care 1996;19(3):257-67.

6. Halliwell B. Reactive oxygen species in living systems: Source, biochemistry, and role in human disease. Am J Med 1991;91(3C):14-22S.

7. Halliwell B, Gutteridge JMC. Lipid peroxidation, oxygen radicals, cell damage, and antioxidant therapy. Lancet 1984;1(8391):1396-7.

8. Hammes HP, Weiss A, Führer D, Krämer HJ, Papavassilis C, Grimminger F. Acceleration of experimental diabetic retinopathy in the rat by omega-3 fatty acids. Diabetologia 1996;39:251-5.
9. Ido Y, Kilo C, Williamson JR. Cytosolic NADH/NAD ${ }^{+}$, free radicals, and vascular dysfunction in early diabetes mellitus. Diabetologia 1997;40:S115-S7.

10. Jain SK, McVie R, Duett J, Herbst JJ. Erythrocyte membrane lipid peroxidation and glycosylated hemoglobin in diabetes. Diabetes 1989;38:1539-43.

11. Jakus $\mathrm{V}$. The role of free radicals, oxidative stress and antioxidant systems in diabetic vascular disease. Bratisl Lek Listy 2000;101(10):541-551.

12. Kanski JJ. Retinal vascular disorders. In: Kanski JJ.Clinical ophthalmolgy: A Systemic Approach. 3rd ed. England: Butterworth \& Heinemann, 1994:344-69.

13. Kelmpner MS, Gallin JI. Separation and functional characterization of human neutrophil subpopulation. Blood 1978;51:659-69.

14. Kesavulu MM, Rao BK, Giri R, Vijaya J, Subramanyam G, Apparao C. Lipid peroxidation and antioxidant enzyme status in Type 2 diabetics with coronary heart disease. Diabetes Res Clin Pract 2001;53(1):33-9.

15. Klein R, Klein BEK. Diabetic eye disease. Lancet 1997;350:197-204.

16. Kowluru RA, Kern TS, Engerman RL, Armstrong D. Abnormalities of retinal metabolism in diabetes or experimental galactosemia. III. Effects of antioxidants. Diabetes 1996;45(9):1233-7.

17. Kowluru RA, Koppolu P, Chakrabarti S, Chen S. Diabetes-induced activation of nuclear transcriptional factor in the retina, and its inhibition by antioxidants. Free Radic Res 2003;37(11):1169-80.

18. Lowry OH, Rosebrough NJ, Farr AL, Randall RJ. Protein measurement with the Folin phenol reagent. J Biol Chem 1951;193:265-75.

19. Luck H. Catalase. In: Bergmeyer HU, ed. Methods in Enzymatic Analysis. New York and London: Academic Press Inc., 1965:855-84.

20. Marhoffer W, Stein M, Maeser E, Federlin K. Impairment of polymorphonuclear leukocyte function and metabolic control of diabetes. Diabetes Care 1992; 15(2):256-60

21. Maxwell SRJ, Thomason H, Sandler D et al. Antioxidant status in patients with uncomplicated insulin-dependent and non-insulin-dependent diabetes mellitus. Eur J Clin Invest 1997;27(6):484-90.

22. Muchova J, Liptakova A, Orszaghova $Z$ et al. Antioxidant systems in polymorphonuclear leucocytes of Type 2 diabetes mellitus. Diabet Med 1999; 16(1):74-8.

23. Ookawara T, Kawamura N, Kitakawa Y, Taniguchi N. Site specific and random fragmentation of $\mathrm{Cu}, \mathrm{Zn}$-superoxide dismutase by glycation reaction. J Biol Chem 1992;267:18505-10

24. Schröder S, Palinski W, Schmid-Schönbein GW. Activated monocytes and granulocytes, capillary nonperfusion, and neovascularization in diabetic retinopathy Am J Pathol 1991;139:81-100.

25. Sinclair AJ, Girling AJ, Gray L et al. An investigation of the relationship between free radical activity and vitamin $\mathrm{C}$ metabolism in elderly diabetic subjects with retinopathy. Gerontology 1992;38:268-74.

26. Strother RM, Thomas TG, Otsyula M, Sanders RA, Watkins JB 3rd. Characterization of oxidative stress in various tissues of diabetic and galactose-fed rats. Int J Exp Diabetes Res 1992;2(3):211-6.

27. Sun Y, Oberlay LW, Li Y. A simple method for clinical assay of superoxide dismutase. Clin Chem 1988;34:497-500.

28. Thornalley PJ. Advanced glycation and the development of diabetic complications: Unifying the involvement of glucose, methylglyoxal and oxidative stress. Endocrinol and Metab 1996;3(3):149-66.

1. Türk, HM, Sevinc, A, Camci, C et al. Plasma lipid peroxidation products and antioxidant enzyme activities in patients with type 2 diabetes mellitus. Acta Diabetol 2002;39(3):117-22.

2. Uchimura $K$, Nagasaka A, Hayashi $R$ et al. Changes in superoxide dismutase activities and concentrations and myeloperoxidase activities in leukocytes from patients with diabetes mellitus. J Diabetes Complications 1999;13(5-6):264-70.

31. Uzel N, Sivas A, Uysal M, Öz H. Erythrocyte LPO and glutathione peroxidase activities in patients with diabetes mellitus. Horm Metabol Res 1987;19:89-90.

32. Vučić M, Gavella M, Božikov V, Ashcroft SJH, Ročić B. Superoxide dismutase activity in lymphocytes and polymorphonuclear cells of diabetic patients. Clin Chem Clin Biochem 1997;35(7):517-21.

33. Yang X, Borg LA, Eriksson UJ. Altered metabolism and superoxide generation in neural tissue of rat embryos exposed to high glucose. Am J Physiol 1997;272(1 Pt 1):E173-E80.

Submitted November 2004

Accepted December 2004.

Assist. Prof. Dr. Naciye Kurtul, Ph.D., University of Kahramanmaras Sütcü Imam, Kahramanmaras, Faculty of Science, Division of Biochemistry, Department of Chemistry, Turkey. e-mail: naciyekurtul@hotmail.com,naciyek@ksu.edu.tr 